\title{
Homemade Kefir Consumption Improves Skin Condition- A Study Conducted in Healthy and Atopic Volunteers
}

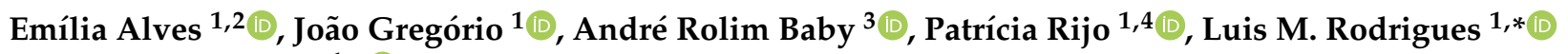 \\ and Catarina Rosado $1, * \mathbb{E}$ \\ 1 CBIOS-Universidade Lusófona's Research Center for Biosciences \& Health Technologies, \\ Campo Grande 376, 1749-024 Lisboa, Portugal; emilia.alves@ulusofona.pt (E.A.); \\ joao.gregorio@ulusofona.pt (J.G.); patricia.rijo@ulusofona.pt (P.R.) \\ 2 Department of Biomedical Sciences, Faculty of Pharmacy, University of Alcalá, Carretera Madrid-Barcelona, \\ Km 33.100, 28805 Alcalá de Henares, Spain \\ 3 Department of Pharmacy, Faculty of Pharmaceutical Pharmacy, University of São Paulo, \\ São Paulo 05508-000, Brazil; andrerb@usp.br \\ 4 Instituto de Investigação do Medicamento (iMed.ULisboa), Faculdade de Farmácia, Universidade de Lisboa, \\ 1649-003 Lisboa, Portugal \\ * Correspondence: monteiro.rodrigues@ulusofona.pt (L.M.R.); catarina.rosado@ulusofona.pt (C.R.)
}

check for updates

Citation: Alves, E.; Gregório, J.; Baby, A.R.; Rijo, P.; Rodrigues, L.M.; Rosado, C. Homemade Kefir Consumption Improves Skin Condition-A Study Conducted in Healthy and Atopic Volunteers. Foods 2021, 10, 2794. https://doi.org/ 10.3390 /foods 10112794

Academic Editor: Mary

Anne Amalaradjou

Received: 20 October 2021

Accepted: 11 November 2021

Published: 13 November 2021

Publisher's Note: MDPI stays neutral with regard to jurisdictional claims in published maps and institutional affiliations.

Copyright: (c) 2021 by the authors. Licensee MDPI, Basel, Switzerland. This article is an open access article distributed under the terms and conditions of the Creative Commons Attribution (CC BY) license (https:/ / creativecommons.org/licenses/by/ $4.0 /)$.

\begin{abstract}
Diet has a fundamental role in the homeostasis of bodily functions, including the skin, which, as an essential protective barrier, plays a crucial role in this balance. The skin and intestine appear to share a series of indirect metabolic pathways, in a dual relationship known as the "gut-skin axis". Hence, the gut-skin axis might be receptive to modulation via dietary modification, where probiotics can be included, thus representing a potential therapeutic target in inflammatory skin diseases, such as atopic dermatitis (AD), in order to control and/or ameliorate symptoms. Kefir is one of the most ancient fermented foods, with probiotic characteristics that have been associated with a wide variety of health-promoting benefits, and it presents a microbiological diversity that makes its application as a probiotic in the gut-skin relationship of the utmost interest. However, the impact of a diet containing kefir on skin health has yet to be reported in scientific literature. This study aimed to assess the impact of the intake of homemade kefir in the skin of healthy and atopic volunteers. The intervention resulted in a boost on barrier function in both skin types verified only in the respective kefir intake groups. An improvement in the degree of severity of AD was also confirmed for the kefir intake group. Atopic individuals may benefit from kefir intake, especially in regard to their skin hydration. Finally, the effects observed on skin barrier function in this study probably culminate from the effects of all the ingredients in kefir, including the complex microbiota, its metabolites and macro- and micronutrients resulting from the fermentation. This work opens the way for more advanced research on the impact of the probiotic kefir on cutaneous health, further clarifying its mechanism of action namely via gut-skin axis.
\end{abstract}

Keywords: kefir; cutaneous health; atopic dermatitis; transepidermal water loss (TEWL); hydration; skin barrier; scoring of atopic dermatitis (SCORAD)

\section{Introduction}

Diet has a fundamental role in the homeostasis of bodily functions, including the functions of the skin, which, as an essential protective barrier, plays a crucial role in this balance [1-3]. The skin and intestine appear to share a series of indirect metabolic pathways in a dual relationship known as the "gut-skin axis" [4-6]. On the one hand, the impairment of the intestinal microbiota is linked to the development of allergic diseases, and the intestinal microbiota and/or dietary metabolites can be detected in the skin. On the other hand, skin health has been linked to the integrity of the intestinal barrier and/or suppression of pro-inflammatory mediators, e.g., via vitamin D [4,7-9]. 
In recent years, growing research in these areas of interest within human nutrition has led to the expansion of probiotics as health promoters $[10,11]$. Probiotics are live microorganisms that, by definition, must confer a health benefit on the host. Probiotics may act via numerous mechanisms, including the restoration of intestinal microbial balance, prevention of pathogen invasion by competitive binding to epithelial cells, suppression of pathogen growth by bacteriocin secretion, and restoration of impaired intestinal barrier function [10,12]. Given that the gastrointestinal mucosa and gut-associated lymphoid tissue harbor more than $70 \%$ of the body's immune cells, this may explain the growth in research data linking these organs to multiple disease mechanisms. This seems to be the case in atopic dermatitis (AD), one of the most prevalent inflammatory skin diseases $[6,7,13]$.

$\mathrm{AD}$ has been associated with an exacerbated skin response to environmental agents, characterized by relevant symptoms including pruritic lesions with typical morphology, pain, and sleep disturbances [1,14]. The onset of AD points towards a complex interaction between skin barrier dysfunction, immune dysregulation, environmental risk factors, and (intestinal and skin) dysbiosis $[1,5,6,15]$. Intestinal dysbiosis seems to increase epithelial permeability via pro-inflammatory cytokines, promote immune dysregulation, and intensify the chronic systemic inflammation in AD $[4-7,9,16]$. Conversely, this also suggests that the gut-skin axis would be receptive to modulation via dietary modification, wherein probiotics can be included, thus representing a potential therapeutic target in $\mathrm{AD}$ to control and/or ameliorate AD symptoms [11,17-19].

Kefir is one of the most ancestral fermented foods with probiotic characteristics [20-23]. Traditionally prepared by the fermentation of milk with kefir grains and most popular in northeastern Europe and Asia, it consists of a symbiotic mixture of lactic acid bacteria (LAB) and yeasts that, in addition to acting synergistically, also produce several bioactive compounds [24-27]. A wide variety of health-promoting benefits have been associated with its use [28-33] and have expanded its popularity beyond its traditional borders within northeaster Europe and Asia. Anti-inflammatory effects [34], antimicrobial activity [35], strengthening of the immune system [36], antioxidant activity [37], and the inhibition of pathogenic microorganisms [24,38] have been reported as a result of kefir consumption. In addition, the topical application of a gel made from a non-microbial fraction of kefir showed an improvement in the wound healing capacity [39]. These properties have been attributed both to the presence of a complex microbiota, with high resistance to passage through the gastrointestinal tract and high adhesion capacity to the intestinal mucus, and to the action of metabolites released during fermentation, namely organic acids and short chain fatty acids (SCFA) [24,37,40-42]. Nevertheless, studies demonstrating its therapeutic interest in specific conditions are very limited, and its potential skin benefits and applicability in the management of AD have yet to be explored.

This study aimed to assess the impact of the regular consumption of kefir prepared in homemade conditions in the skin of healthy and atopic volunteers.

\section{Materials and Methods}

\subsection{Study Design}

A controlled intervention study, coded DermapBio, was conducted according to the principles of the Helsinki Declaration and after informed consent. The study protocol was approved by the ethics committee of the School of Sciences and Health Technologies at Lusofona University ( $\mathrm{N}^{\circ} 1 / 2018,15$ May 2018). Study subjects were recruited by convenience sampling between October 2019 and December 2020. Subjects were asked to answer a questionnaire that examined sociodemographic and lifestyle conditions, as well as specific inclusion/exclusion criteria. These criteria are summarized in Table 1. 
Table 1. General inclusion and exclusion criteria and atopic group specific inclusion criteria.

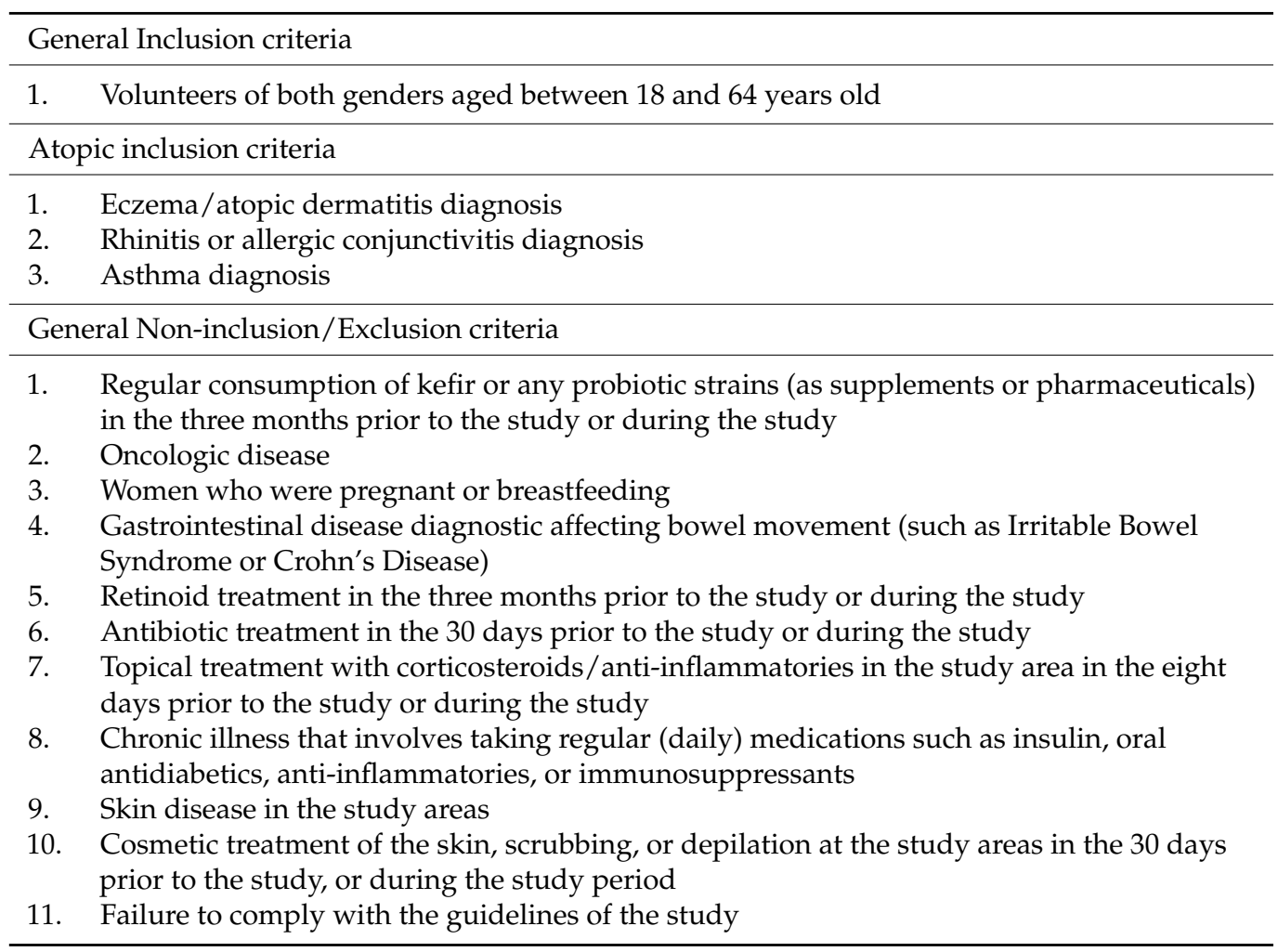

Subjects were assigned to the different groups according to the inclusion criteria. The atopic group $(n=19)$ included 1 male and 18 females, aged between 19 and 56 years (mean age $31.7 \pm 11.9$ years), wherein $47 \%$ were under 30 years old. Within this group, all subjects along with presented with AD; 14 (74\%) of the subjects within this group also reported rhinitis, and $6(32 \%)$ reported asthma diagnosis. All other subjects who fulfilled the eligibility criteria, excluding the atopic criteria, and were free of skin diseases, including $\mathrm{AD}$, psoriasis, and other systemic diseases that may impact skin condition, were assigned to the healthy group. These subjects $(n=33)$ included 6 males $(18 \%)$ and 27 females $(82 \%)$, aged between 20 and 60 years (mean age $27.0 \pm 10.1$ years), wherein $61 \%$ were under 30 years old. Within each group, volunteers were assigned to either the kefir intake or the control (without intake) group, according to their preference.

This research aimed to compare, for each skin type evaluated, the effect of kefir ingestion between the intervention groups and respective controls, thus using a parallel group design. However, this design is unable to distinguish between changes induced by food ingestion and those induced by differences between individuals at baseline [43]. Therefore, in order to minimize baseline individual variability, especially in studies involving dietary interventions, a crossover design is recommended as individuals are used as their own controls (paired comparisons) $[43,44]$. Hence, a crossover design was then sequentially applied to each study group, since, for each individual, a comparison was made between the parameters measured before and after the intervention (Figure 1).

All subjects were instructed to proceed as follows during the study period: avoid overexercising and major lifestyle changes; not consume dietary supplements or fermented foods; not change their usual dietary intake of food fiber or food containing oligosaccharides; refrain from using laxatives; refrain from changing type and frequency of regularly used skin-care agents; avoid travelling abroad. 


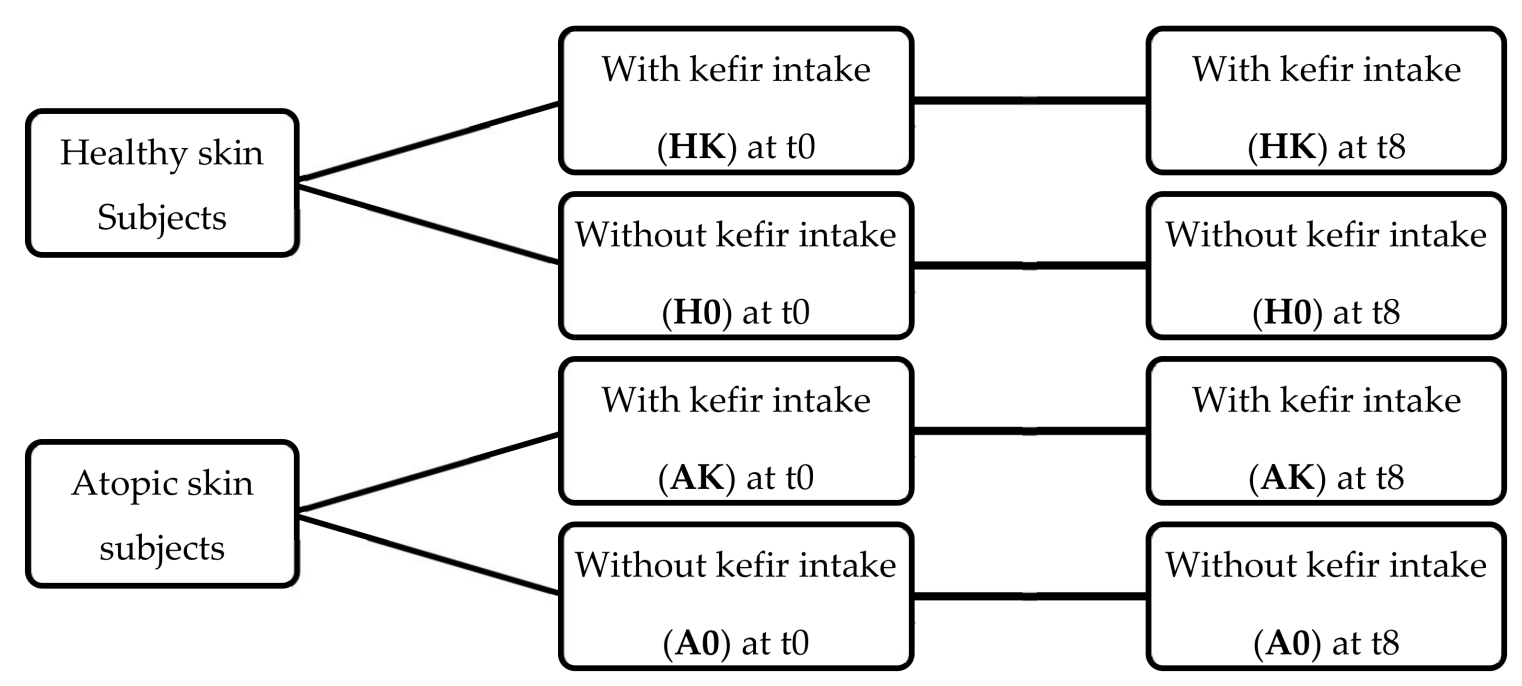

Figure 1. Study design regarding skin conditions and kefir intake during the eight-week intervention period: HK-healthy skin with kefir intake; H0-healthy skin without kefir intake; AK—atopic skin with kefir intake; A0—atopic skin without kefir intake.

Physiological conditions, skin phototype, and anthropometric measurements (weight, height, and waist circumference) were obtained from all the participants. The skin phototype was assessed (by a single researcher) using the Fitzpatrick phototype classification [45]. Height was self-reported, weight was measured using a digital weight scale Tanita ${ }^{\circledR}$ BC601 (Tanita Europe BV, Amsterdam, the Netherlands), and waist circumference (WC) was measured using a Kern ${ }^{\circledR}$ MSW circumference tape measure (KERN \& SOHN GmbH, Balingen, Germany). Body Mass Index (BMI) was calculated as weight (kg)/(height (m)2 ${ }^{2}$ [46].

The control groups, $\mathrm{A} 0$ and $\mathrm{H} 0$, did not consume kefir. The intervention in groups AK (atopic skin with kefir intake) and HK (healthy skin with kefir intake) consisted of the daily consumption of kefir for eight weeks. This period has been adopted in similar trials [47-52], and is supported by the fact that approximately two weeks are required for the development of a consistent probiotic gut colonisation, i.e., stable detection in faecal content, and approximately one month to observe a significant change in cytokines at the gut level. Thus, the period of eight weeks, being sufficient to impact the bowel, would also be long enough for a putative effect on the skin.

The primary endpoints in this study were a decrease in transepidermal water loss (TEWL) and an increase in stratum corneum (SC) hydration for all subjects, and a decrease in the SCORAD Index for atopic subjects.

\subsection{Assessment of Dietary Intake}

Dietary intake was assessed at baseline, for all subjects, through a three-day dietary record (two weekdays and one weekend day) $[53,54]$. Detailed instructions for recordkeeping were provided in writing to all subjects.

\subsection{Kefir Intervention}

Kefir grains CIDCA AGK1 were obtained from the Centro de Investigación y Desarrollo en Criotecnología de Alimentos (CIDCA), La Plata, Argentina. Microbiological characterization, preservation, and storage of these grains have been described elsewhere [55-57]. Kefir was produced by fermentation of a commercial ultra-high temperature pasteurized (UHT) semiskimmed cow milk of Portuguese provenance (Nova Açores ${ }^{\circledR}$, S. Miguel, Portugal), with CIDCA AGK1 kefir grains using a grain inoculum of $10 \%(w / v)$, for $24 \mathrm{~h}$, at a temperature of $20 \pm 1^{\circ} \mathrm{C}$. The fermentation conditions were designed to be representative of Portuguese household conditions, as described elsewhere [27]. In order to assure the daily intake of kefir for eight consecutive weeks, each subject of both intake groups (AK or HK) visited the research center three times a week (Monday, Wednesday and Friday). During the 
visit, the subjects drank $100 \mathrm{~mL}$ of kefir and were given white plastic sterile containers with the kefir doses of the following days. The subjects were instructed to store these kefir samples in their household refrigerator to maintain their characteristics [27]. It was determined that $100 \mathrm{~mL}$ of the prepared kefir had a nutritional composition of $1.28 \pm 0.04 \mathrm{~g}$ of fat, $3.15 \pm 0.19 \mathrm{~g}$ of protein and $4.91 \pm 0.19 \mathrm{~g}$ of carbohydrates and $0.6 \mathrm{~g}$ of lactic acid. Microbiologically, it provided $7 \times 10^{9}$ colony-forming units (CFU) of LAB and $2 \times 10^{8} \mathrm{CFU}$ of yeast [27], which is consistent with the literature for the daily ingestion of probiotic bacteria capable of surviving passage through the gastrointestinal tract and thus reaching the necessary sites to exercise their positive physiological functions, both intestinal and immunological $[58,59]$.

\subsection{Skin Measurements}

The skin condition was quantitatively evaluated by non-invasive bioengineering equipment, including those assessing TEWL, SC hydration, and erythema, which is a sign of exacerbation in AD [60-62]. TEWL, a measure of the rate of water lost through the skin, reflects barrier dysfunction directly, thus being a parameter of interest to evaluate skin barrier function in both healthy and diseased skin [60,63]. It was measured using a Tewameter ${ }^{\circledR}$ TM300 (Courage + Khazaka Electronic GmbH, Köln, Germany) in accordance with the published guidelines [64], and measurements were expressed as $\mathrm{g} / \mathrm{m}^{2} / \mathrm{h}$. Skin hydration is indicative of the water content of the SC, which is also a parameter of interest in both healthy and atopic skin [61,62]. It was measured using a Corneometer ${ }^{\circledR}$ CM825 (Courage + Khazaka Electronic GmbH, Köln, Germany) and was assessed as skin conductance given by the reactive capacitance of skin, using the stratum corneum as a dielectric membrane [65]. Measurements were expressed in arbitrary units (AU).

All participants were advised to refrain from using moisturizers or other cosmetic products in the tested areas $48 \mathrm{~h}$ before the measurements. Measurement areas were assigned in the ventral forearm ( $10 \mathrm{~cm}$ below the inner elbow crease), leg (outer side, $10 \mathrm{~cm}$ below the knee), and forehead (mid area). Measurements were taken in all subjects before and after the eight weeks of intervention, $\mathrm{t} 0$ and $\mathrm{t} 8$, respectively, and were performed by the same researcher using identical standards. Measurements were performed under controlled temperature $\left(21 \pm 1{ }^{\circ} \mathrm{C}\right)$ and humidity conditions (relative humidity, $50 \pm 10 \%$ ) after a period of acclimatization of $20 \mathrm{~min}$.

As shown in a previous study, the use of a stress test to assess the skin barrier function after a probiotic intervention represents a novel approach in this field [63]. Therefore, a sodium lauryl sulfate (SLS)-induced skin lesion model was applied at baseline (t0) and after the intervention period ( $t 8)$. This test, consisting of the application of a $1 \%$ solution of SLS under occlusion for $24 \mathrm{~h}$, was conducted in the forearm and only on volunteers with healthy skin, as the application of SLS would be detrimental to the volunteers in the atopic group, potentially causing excessive discomfort. The extent of the impact of SLS was assessed by evaluation of TEWL combined with measurement of erythema as described elsewhere [63] using a Chroma Meter ${ }^{\circledR}$ CR300 (Konica Minolta, Tokyo, Japan) and expressed as $\mathrm{a}^{*}$ in the $\mathrm{L}^{*} \mathrm{a}^{*} \mathrm{~b}^{*}$ system color [66].

\subsection{SCORAD Index Assessment}

The standard scoring system of Atopic Dermatitis-SCORAD Index, developed by the European Task Force Group on Atopic Dermatitis (ETFAD), considered the best validated scoring system to assess AD clinical severity, was applied in this study $[67,68]$. This severity classification system contemplates two distinct scores: the objective SCORAD score (intensity and extent of the lesions), which ranges from 0 to 83; and the subjective SCORAD score (pruritus and sleep loss), which extends the SCORAD total score to a maximum of 103. The objective SCORAD score is divided into part A, consisting of the interpretation of the extent of the disorder, which represents the affected body sites, and part $\mathrm{B}$ representing the intensity of the lesions. The subjective SCORAD score is given by 
part C, consisting of symptoms such as itching and sleep loss during the three days prior, and is scored by the patients. SCORAD Index is determined by [68]:

$$
\text { SCORAD Index }=\frac{A}{5}+\frac{7 B}{2}+C
$$

The SCORAD Index was assessed at $\mathrm{t} 0$ and $\mathrm{t} 8$ (only) in the atopic group by the same researcher using identical criteria. Considering the ETFAD recommendation, the $\mathrm{AD}$ severity was classified as mild for SCORAD Index $<25$, as moderate for SCORAD Index between 25-50, and as severe for SCORAD Index > 50 [67].

\subsection{Statistical Analysis}

Results were expressed as mean \pm standard deviation (SD), as relative frequencies, or as median and first and third quartiles. Since the data were not normally distributed (normality assessed by the Shapiro-Wilk test), non-parametric tests were chosen to test different hypotheses. For continuous variables, differences within individuals were identified by Wilcoxon signed rank test and differences between kefir intake and control groups by Mann-Whitney U test. The Chi-square test was used to test associations between categorical variables. Pearson's correlation was used to evaluate possible relations between skin barrier function parameters and the severity of $\mathrm{AD}$. Linear regressions were used to evaluate the association between kefir intake and skin improvements and their potential confounding factors. All analyses were performed using the SPSS statistical package version 25 (SPSS Inc., Chicago, IL, USA) with a significance level of 0.05 .

\section{Results}

\subsection{Study Groups Characteristics}

Before the beginning of the intervention, socio-demographic characteristics were assessed (Supplementary Table S1). Data concerning daily food intake were also collected (Supplementary Table S2). The physiological characteristics are presented in Table 2.

Table 2. Physiological characteristics of study participants (relative frequency (\%); mean $\pm \mathrm{SD}$ ).

\begin{tabular}{|c|c|c|c|c|c|c|}
\hline \multirow{2}{*}{$\begin{array}{l}\text { Physiological } \\
\text { Characteristics }\end{array}$} & \multicolumn{3}{|c|}{$\begin{array}{l}\text { Healthy Group } \\
\quad(n=33)\end{array}$} & \multicolumn{3}{|c|}{$\begin{array}{l}\text { Atopic Group } \\
\quad(n=19)\end{array}$} \\
\hline & HK & Ho & $p$-Value & AK & A0 & $p$-Value \\
\hline \multicolumn{7}{|l|}{ Gender } \\
\hline Female, n (\%) & $12(92.3)$ & $15(75.0)$ & 0.208 & $9(100)$ & $9(90.0)$ & 0.330 \\
\hline Male, n (\%) & $1(7.7)$ & $5(25.0)$ & & 0 & $1(10.0)$ & \\
\hline Age, mean (SD), years & $28.9(13.0)$ & $25.8(7.71)$ & $0.739 *$ & $30.4(12.3)$ & $32.9(12.1)$ & $0.538^{*}$ \\
\hline \multicolumn{7}{|l|}{ Skin Phototype } \\
\hline Type II, n (\%) & $6(46.2)$ & $7(35.0)$ & & $4(44.4)$ & $2(20.0)$ & \\
\hline Type III, n (\%) & $5(38.5)$ & $12(60.0)$ & 0.388 & $5(55.6)$ & $8(80.0)$ & 0.252 \\
\hline Type IV n (\%) & $2(15.3)$ & $1(5.0)$ & & 0 & 0 & \\
\hline BMI, mean (SD), kg $/ \mathrm{m}^{2}$ & $22.6(3.68)$ & $23.3(4.19)$ & $0.439 *$ & $22.7(3.40)$ & $22.8(2.18)$ & $0.540 *$ \\
\hline Waist circumference, mean (SD), cm & $72.4(9.19)$ & $77.5(13.6)$ & $0.328 *$ & $77.2(8.67)$ & $78.6(6.02)$ & 0.653 * \\
\hline
\end{tabular}

Despite the different sample sizes of the groups, subjects who were given kefir, either healthy or atopic, showed no differences in physiological characteristics, regarding the respective control groups, at baseline, as shown in Table 2. In addition, no differences were found for lifestyle indicators, such as cigarettes and alcohol consumption, nor dairy intake (Supplementary Table S1). All groups presented a mean BMI below $24.9 \mathrm{~kg} / \mathrm{m}^{2}$, representative of normal weight, and a mean $W C$ below $80 \mathrm{~cm}$, considered within the 
normal range for both men and women, thus indicating low risk of metabolic diseases [69]. Regarding the dietary intake, no differences were observed for energy, macronutrients, and water, between subjects who drank kefir, either healthy or atopic, and their respective controls (Supplementary Table S2). Although all macronutrients (assessed as a percentage of the energy intake) were within the recommended range, fiber intake was found to be lower than the recommendation [70]. These data indicate identical baseline characteristics and conditions for the intervention among kefir intake and control for both healthy and atopic groups.

\subsection{Skin Measurements}

Skin condition was assessed by measuring TEWL, SC hydration, and erythema, at t0 and at $\mathrm{t} 8$.

An analysis of the variation of skin parameters after eight weeks was conducted, comparing kefir intake and control groups in both healthy and atopic volunteers (Table 3). In order to minimize the impact of interindividual variability, for this comparison, variation on skin parameters was computed as a deviation from baseline, calculated as:

$$
\text { Deviation }(\text { variable })=[(\text { variable at } t 8)-(\text { variable at } t 0)] /(\text { variable at } t 0)
$$

Table 3. Comparison of skin parameters variation, between kefir intake and control groups, for both healthy and atopic volunteers, after eight weeks of kefir ingestion (median (Q1, Q3)).

\begin{tabular}{|c|c|c|c|c|c|c|}
\hline \multirow{2}{*}{$\begin{array}{c}\text { Deviation of } \\
\text { Skin Parameters }\end{array}$} & \multicolumn{3}{|c|}{$\begin{array}{l}\text { Healthy Group } \\
\quad(n=33)\end{array}$} & \multicolumn{3}{|c|}{$\begin{array}{l}\text { Atopic Group } \\
\quad(n=19)\end{array}$} \\
\hline & HK & Ho & $p$-Value & AK & A0 & $p$-Value \\
\hline \multicolumn{7}{|l|}{ TEWL } \\
\hline Forearm & $\begin{array}{c}-0.302 \\
(-0.489,0.0149)\end{array}$ & $\begin{array}{c}0.0058 \\
(-0.12,0.081)\end{array}$ & 0.018 & $\begin{array}{c}-0.529 \\
(-0.601,-0.428)\end{array}$ & $\begin{array}{c}0.148 \\
(-0.571,0.578)\end{array}$ & $<0.001$ \\
\hline Leg & $\begin{array}{c}-0.0976 \\
(-0.321,0.244)\end{array}$ & $\begin{array}{c}0.0143 \\
(-0.248,0.116)\end{array}$ & 0.854 & $\begin{array}{c}-0.288 \\
(-0.333,-0.176)\end{array}$ & $\begin{array}{c}0.507 \\
(0.0656,1.36)\end{array}$ & $<0.001$ \\
\hline Forehead & $\begin{array}{c}-0.220 \\
(-0.375,-0.0448)\end{array}$ & $\begin{array}{c}-0.0128 \\
(-0.196,0.152)\end{array}$ & 0.036 & $\begin{array}{c}-0.457 \\
(-0.612,-0.243)\end{array}$ & $\begin{array}{c}0.150 \\
(-0.0571,0.636)\end{array}$ & $<0.001$ \\
\hline \multicolumn{7}{|l|}{ Hydration } \\
\hline Forearm & $\begin{array}{c}-0.0196 \\
(-0.0784,0.0959)\end{array}$ & $\begin{array}{c}-0.184 \\
(-0.256,-0.0132)\end{array}$ & 0.034 & $\begin{array}{c}0.452 \\
(0.300,0.560)\end{array}$ & $\begin{array}{c}-0.0810 \\
(-0.282,0.119)\end{array}$ & 0.001 \\
\hline Leg & $\begin{array}{c}0.143 \\
(-0.134,0.212)\end{array}$ & $\begin{array}{c}-0.0270 \\
(-0.246,0.0896)\end{array}$ & 0.320 & $\begin{array}{c}0.250 \\
(0.213,0.522)\end{array}$ & $\begin{array}{c}0.0470 \\
(-0.0894,0.220)\end{array}$ & 0.034 \\
\hline Forehead & $\begin{array}{c}0.128 \\
(-0.0447,0.373)\end{array}$ & $\begin{array}{c}-0.127 \\
(-0.325,0.0356)\end{array}$ & 0.012 & $\begin{array}{c}0.244 \\
(0.146,0.537)\end{array}$ & $\begin{array}{c}0.0450 \\
(-0.297,0.466)\end{array}$ & 0.086 \\
\hline \multicolumn{7}{|l|}{ Erythema } \\
\hline Forearm & $\begin{array}{c}-0.0556 \\
(-0.186,-0.0170)\end{array}$ & $\begin{array}{c}-0.0745 \\
(-0.111,0.0119)\end{array}$ & 0.685 & $\begin{array}{c}-0.133 \\
(-0.185,-0.0692)\end{array}$ & $\begin{array}{c}-0.0404 \\
(-0.191,0.129)\end{array}$ & 0.221 \\
\hline
\end{tabular}

Q1—first quartile; Q3—-third quartile. HK—healthy skin with kefir intake; H0—healthy skin without kefir intake; AK—atopic skin with kefir intake; A0-atopic skin without kefir intake. TEWL—transepidermal water loss. Groups compared by Mann-Whitney U test, with $p<0.05$ for statistical significance.

Deviation variables must be interpreted as follows: for TEWL and erythema, negative values represent an improvement in skin condition after the intervention, while for hydration, an improvement is only observed when the deviation value is positive.

As shown in Table 3, on the healthy skin volunteers, forearm and forehead TEWL decreased in the HK group compared to H0 group ( $p=0.018$ and $p=0.036$, respectively). Moreover, the kefir-supplemented group showed increased forearm and forehead hydration, compared to the control ( $p=0.034$ and $p=0.012$, respectively). No differences were observed between HK and H0 for erythema $(p=0.685)$. These results are supported by those obtained in individual paired comparisons that showed that after eight weeks of kefir ingestion, on healthy subjects, forearm and forehead TEWL and erythema decreased significantly compared to to $(p=0.016, p=0.019$, and $p=0.023$, respectively) (Supplementary Table S3), thus confirming the effective improvement in skin conditions.

Furthermore, results from application of the SLS induction lesion model on healthy skin, performed at $\mathrm{t} 0$ and $\mathrm{t} 8$, are shown in Table 4 . 
Table 4. Variation of skin parameters, after lesion induction with SLS, for the healthy group (median (Q1, Q3)).

\begin{tabular}{lccc}
\hline $\begin{array}{l}\text { Deviation of Skin } \\
\text { Parameters }\end{array}$ & \multicolumn{3}{c}{$\begin{array}{c}\text { Healthy Group } \\
(n=33)\end{array}$} \\
\cline { 2 - 4 } at Forearm & HK & $0.0878(-0.0924,0.243)$ & $<$-Value \\
\hline TEWL SLS & $-0.2931(-0.510,-0.180)$ & 0.001 \\
Hydration SLS & $0.0000(-0.133,0.106)$ & $0.0065(-0.0889,0.138)$ & 0.347 \\
Erythema SLS & $-0.0287(-0.0371,0.0644)$ & $0.0144(-0.0775,0.135)$ & 0.825 \\
\hline Q1-first quartile; Q3-third quartile. Deviation (variable) $=[$ (variable at t8) $-($ variable at t0)]/(variable \\
at t0). HK—healthy skin with kefir intake; H0-healthy skin without kefir intake; TEWL-transepidermal \\
water loss. SLS-sodium lauryl sulphate. Groups compared by Mann-Whitney U test, with $p<0.05$ for \\
statistical significance.
\end{tabular}

The results from Table 4 showed a significant decrease in TEWL on the HK group compared to control $(p<0.001)$, thus corroborating the above-mentioned results for forearm TEWL, shown in Table 3.

For atopic skin subjects, variations on skin parameters were noted in the AK group after eight weeks (Table 3). TEWL decreased in the forearm (the more significant change), forehead, and leg, compared to the A0 group ( $p<0.001$, for all cases). Regarding hydration, the AK group showed an increase in forearm and leg compared to control $(p=0.001$ and $p=0.034$, respectively). No differences were observed for erythema $(p=0.221)$ between these groups (Table 3). These results were reinforced by those from individual paired comparisons that showed that at $\mathrm{t} 8$, the atopic subjects who drank kefir presented a significantly lower TEWL and erythema and a significantly higher hydration compared to t0 in all anatomical study areas ( $p<0.05$, for all parameters), while in the control group, no differences were observed (Supplementary Table S3), thus confirming the effective change in skin conditions, despite individual baseline conditions.

\subsection{SCORAD Index Assessment}

The SCORAD Index was evaluated at $\mathrm{t} 0$ and $\mathrm{t} 8$ for all subjects from the atopic group. Variation on the SCORAD Index was assessed as a deviation and was computed using the previously explained approach; thus, negative values represent an improvement in $\mathrm{AD}$ symptoms after the intervention. The results are shown in Table 5.

Table 5. Comparison of SCORAD Index variation, between kefir intake and control, for atopic group, after intervention (median (Q1, Q3)).

\begin{tabular}{lccc}
\hline $\begin{array}{l}\text { Deviation of } \\
\text { SCORAD Index }\end{array}$ & AK & $\begin{array}{c}\text { Atopic Group } \\
(\boldsymbol{n}=\mathbf{1 9 )}\end{array}$ & \\
\cline { 2 - 4 } & -0.626 & A0 & $p$-Value \\
\hline SCORAD & $(-0.758,-0.491)$ & $(-0.0293,0.273)$ & $<0.001$ \\
\hline
\end{tabular}

Q1—first quartile; Q3-third quartile. SCORAD—SCORing of Atopic Dermatitis. AK—atopic skin with kefir intake; A0-atopic skin without kefir intake. Groups compared by Mann-Whitney U test, with $p<0.05$ for statistical significance.

As shown in Table 5, after eight weeks of kefir intake, the AK group showed a significant decrease in the SCORAD Index, compared to control $(p<0.001)$. These results were corroborated by those of paired individual comparisons in which at $\mathrm{t} 8$ atopic individuals who drank kefir had a significantly lower SCORAD index compared to t0 $(p<0.05)$, whereas for control individuals, no differences were observed (see Supplementary Table S3), thus confirming the effective change in skin conditions despite individual baseline conditions.

It is noteworthy that, at the beginning of the study, the AK group presented a median SCORAD Index value of $61.9(41.2,72.2)$, a range classified as severe AD, while after the intervention with kefir, the median SCORAD Index was $16.2(12.1,32.9)$, a range classified 
as mild $\mathrm{AD}$, according to the ETFAD recommendation [67]. As for group $\mathrm{A} 0$, the median SCORAD Index value was $33.4(23.1,52.1)$ at $t 0$ and $33.9(26.8,69.4)$ at t8, thus classifying the severity of $\mathrm{AD}$ as moderate both at baseline and after the intervention period.

Furthermore, in atopic volunteers, a possible relationship between cutaneous parameters and the AD severity was also assessed using Pearson's correlation. We observed a significant correlation between the improvement of $\mathrm{AD}$ severity given by the deviation of the SCORAD Index and skin barrier improvement given by the deviation of TEWL on the forearm, leg, and forehead $(\mathrm{r}=0.630, p=0.004 ; \mathrm{r}=0.481, p=0.037 ; \mathrm{r}=0.680$, $p=0.001$, respectively), and also on the forearm hydration $(\mathrm{r}=-0.839, p<0.001)$. Although erythema, a well-known sign of skin inflammation, is present in both acute and chronic stages of $\mathrm{AD}$ [60], our results were not able to detect a relation between erythema and the improvement of AD severity $(r=0.286, p=0.236)$.

\subsection{Adjusted Models for Skin Parameters}

To assess the effect of different independent variables on the outcomes of skin parameters, multiple linear regression models were performed. All socio-demographic variables, food intake variables, kefir intake, and skin status were considered as possible predictors for the influence in deviation of skin parameters. After testing the assumptions for linear regression and collinearity diagnostics, independent variables were excluded from the models if the variance inflation factor (VIF) was superior to 10. Following this step, backward stepwise linear regressions were performed for each outcome variable to identify which variables better explained the outcome variable. Although the climatic conditions (temperature and humidity) were evaluated at $\mathrm{t} 0$ and $\mathrm{t} 8$, they were not used in the regression models as they did not affect the effect of kefir intake $(p=0.329, p=0.464, p=0.352$ and $p=0.363$, respectively), thus not being considered relevant.

The most common variables in the models and so considered as possible predictor variables on skin parameters identified by this method were: kefir status, defined as with or without kefir intake; skin status, defined as belonging to the healthy or the atopic group; gender, defined as male or female; and water intake in liters. New linear regressions with the Enter method were then run, which are presented in Table 6.

Table 6. Multiple linear regression for effect of kefir status on skin parameters (standardized regression coefficient $ß$ ( $p$-value), $n=52$ ).

\begin{tabular}{lccc}
\hline \multirow{2}{*}{$\begin{array}{c}\text { Deviation of } \\
\text { Skin Parameters }\end{array}$} & Model 1 & M for Kefir Intake $(p$-Value) \\
\cline { 2 - 4 } & & Model 2 & Model 3 \\
\hline TEWL & $-0.596(<0.001)$ & $-0.597(<0.001)$ & $-0.625(<0.001)$ \\
Forearm & $-0.304(0.029)$ & $-0.323(0.018)$ & $-0.332(0.020)$ \\
Leg & $-0.501(<0.001)$ & $-0.502(<0.001)$ & $-0.524(<0.001)$ \\
Forehead & & & \\
Hydration & $0.481(<0.001)$ & $0.458(<0.001)$ & $0.539(<0.001) \mathrm{a}$ \\
$\quad$ Forearm & $0.294(0.034)$ & $0.267(0.042)$ & $0.347(0.006) \mathrm{a}$ \\
Leg & $0.362(0.008)$ & $0.346(0.011)$ & $0.358(0.012)$ \\
$\quad$ Forehead & $-0.910(<0.001)$ & n.a. & $-0.866(<0.001)$ \\
SCORAD Index $(* *)$ &
\end{tabular}

$\beta$-standardized regression coefficient (reference category: without kefir intake), $p<0.05$ for statistical significance. Model 1-kefir Status; Model 2-kefir status, skin status; Model 3-kefir status, skin status, gender; water intake. $\left.{ }^{(* *}\right)$ Variable skin status was excluded from the models. n.a.-not applicable. a-gender and water contribution showed $p<0.05$. TEWL—transepidermal water loss. SCORAD—SCORing of Atopic Dermatitis.

The results from Table 6 show that drinking kefir for eight weeks is associated with a significant improvement in TEWL and in SC hydration, in all study areas (Model 1). In the adjusted models for skin status (Model 2) and skin status, gender, and water intake (Model 3 ), the effect of kefir intake remained significant, continuing to show an improvement in TEWL and hydration, with the best results obtained for the forearm. The SCORAD Index clearly improved with kefir intake. 


\section{Discussion}

New insights in the field of nutrition increasingly support the evidence of a close relationship between diet and health, namely skin health [2,71]. Diet is a major regulator of the intestinal microbiota, and short-term changes in the diet have the ability to rapidly alter gut bacteria $[44,72]$. The use of probiotics presents itself as one of the most common interventions to beneficially regulate the gut microbiota [2,10,71]. Probiotics are beginning to be recognized as being able to beneficially impact skin health by modifying its microbiota, preventing pathogen invasion and contributing to the restoration of impaired barrier function [13,73-75].

The consumption of kefir has been reported to positively impact the gut microbiota and overall condition of the digestive system [33,76-78]. Additionally, an in vitro study suggests that kefir's passage through the human gastrointestinal tract, and its consequent digestion, can improve its nutritional profile and bioactivity [79]. However, to date, most studies aiming to establish the benefits to human health of kefir consumption have been based in animal models, or in cell culture systems wherein the digestion of kefir does not occur, thus providing limited information [28,79]. Of note, none of the in vivo human studies found in the literature observed the skin impact of a diet containing traditionally homemade kefir as the probiotic, neither in healthy nor atopic subjects.

In this study, kefir intake for eight weeks caused an improvement in the skin condition of healthy subjects, quantitatively demonstrated by a significant decrease in TEWL and increase in hydration on the forearm and forehead, compared to the control. Similar results were found in other in vivo studies evaluating the effect of ingested specific probiotic strains (Lactobacillus and Bifidobacterium species) in human adults with healthy skin [48,49,80-82]. Kano et al. and Mori et al. evaluated the effect of ingesting fermented milk containing one strain of Bifidobacterium species for eight weeks. They both found a significant improvement on SC hydration in the probiotic ingestion group, and attributed their results to an improvement in intestinal conditions, as the levels of toxic metabolites excreted by intestinal bacteria such as phenol decreased [81,82]. In the study by Gueniche et al., a significant decrease in TEWL was observed after eight weeks of probiotic intervention [48]. Moreover, Ogawa et al. found a significant decrease in TEWL and an increase in SC hydration after twelve weeks of probiotic intake [49], and Lee et al. observed identical results after twelve weeks of probiotic intake [80]. However, not all skin studies using probiotics have been able to demonstrate this type of outcome. Saito et al. tested the ingestion of one probiotic strain (Lactobacillus species) by healthy volunteers and found a decrease in TEWL at the arm, but not the face, and was not able to detect changes in skin hydration [47].

An innovative note in our approach is the use of the SLS irritation induction model to further demonstrate the beneficial impact of kefir consumption in barrier function in healthy skin. These results are supported by previous research by the authors [63]. Other studies using similar approaches but conducted in animal models exposed to irritants (ex vivo and in vivo) observed a decrease in TEWL after ingesting probiotics [83,84].

Atopic dermatitis (AD), the most common form of eczema, is a chronic inflammatory skin disease characterized by symptoms such as pruritic lesions, pain, and sleep disturbances $[1,15]$. AD onset points towards a complex interaction between skin barrier dysfunction, immune dysregulation, environmental risk factors, and dysbiosis of the intestinal and skin microbiota, which correlates with the clinical severity of $\mathrm{AD}[1,14,15,61]$. Through the gut-skin axis, intestinal dysbiosis has been shown to negatively impact skin function either through an increase of epithelial permeability, via pro-inflammatory cytokines, thus promoting immune dysregulation and contributing to the chronic systemic inflammation in $\mathrm{AD}$, as by perpetuating pruritus via secretion of neuroendocrine itch mediators, leading to a chronic itch-scratch cycle, thus further disrupting the skin barrier $[1,5,6,9]$.

In $\mathrm{AD}$, the presence of an impaired epidermal skin barrier is demonstrated by both a defective inside-outside barrier (increased TEWL) as well as a defective outside-inside barrier (increased penetration of environmental substances triggering immunological 
mechanisms), along with decreased hydration of the SC [1,14,15]. A lower content in SC ceramides, unsaturated fatty acids, and structural proteins such as filaggrin (involved in SC barrier formation and hydration) underlies the cutaneous barrier dysfunction in $\mathrm{AD}[1,74,85]$. Traditional therapy used in $\mathrm{AD}$ is based on topical treatments, often corticosteroids, thus being focused on treating symptoms rather than the underlying causes, therefore mainly resulting in a short-term repair of the defective barrier $[1,85,86]$.

Although to date several studies have explored the potential efficacy of probiotics in the prevention and treatment of $\mathrm{AD}$, the results are not consistent, thus contributing to the lack of evidence for the use of probiotics in skin health $[11,73,75,85-87]$. The variation in types of strains used, both in diversity and in doses, different types of formulation (supplement or food), duration of the ingestion period, as well as the type of parameters used to assess skin conditions can somehow justify this lack of consistency in the results obtained [86].

In our study, a significant decrease in TEWL and increase in hydration was observed in subjects with $\mathrm{AD}$ who drank kefir for eight weeks in all the anatomical areas of study, which was not observed in the controls. Furthermore, our data also showed a significant decrease in the SCORAD index in the kefir ingestion group compared to controls, with the level of AD severity changing from severe to mild, which reflects a notable clinical improvement. These results are in agreement with similar in vivo studies conducted on other probiotics $[50,51,88,89]$. In a randomized cross-over study using a combination of the probiotics (Lactobacillus and Bifidobacterium species) delivered as food (yogurt) for eight weeks, Roessler et al. observed a non-significant decrease in SCORAD in the atopic group only [50]. Similarly, Yoshida et al. supplemented adults with AD for eight weeks using a capsule formulation with one probiotic strain (Bifidobacterium species) and found a significant decrease in SCORAD only in the probiotic intake group, which was attributed to changes in intestinal microflora [51]. In another study, Iemoli et al. found an improvement in SCORAD in adults with AD after a twelve-week intake of a freeze-dried powder mixture of two probiotics (Lactobacillus and Bifidobacterium species), and justified this by an improvement in the immune response, namely, by the increased production of T-helper cell type-2 (Th2) and regulatory T cells, and by the reduction of microbial translocation in the intestine [90]. Drago et al. observed identical results after a 16 week intervention with sachets containing one Lactobacillus species, in AD volunteers, and attributed them to a significant decrease of T-helper cell type-1 (Th1) inflammatory cytokines and Th1/Th2 ratio [88]. These studies highlight the microbiota's ability to impact the lymphoid tissue associated with the intestine, via microbial-mucosal interaction $[6,13]$. To date, the only meta-analysis performed evaluating the effect of oral probiotics in adults with AD found an overall improvement in the SCORAD index $(-8.26,95 \%$ CI: $-13.28,-3.25)$ favoring probiotics [87]. Moreover, a minimum intervention time of eight weeks has also been shown to be adequate to assess the impact of probiotics on AD [87]. Finally, and in contrast to our study, Matsumuto et al. were not able to find any differences in AD severity between probiotic and control groups using one strain of Bifidobacterium delivered in the form of capsules to AD patients for eight weeks [52].

Furthermore, in studies that assess the impact of probiotics on AD, typically, only clinical parameters are evaluated, usually severity using the SCORAD Index or equivalents $[11,75,86,90]$. Our approach, combining clinical and skin barrier function assessment, revealed a strong correlation between the improvement in both the severity of skin lesions and TEWL, thus confirming previous reports on the relationship between TEWL and the clinical status of patients with $\mathrm{AD}[60,89]$.

Additionally, no differences in erythema were observed between the study groups in our study, which can be explained by the fact that although erythema is particularly associated with acute skin inflammation, it can also be present in both the acute and chronic stages of the disease; similar results were found in the literature [60]. This may be indicative that erythema measurement is not as sensitive as the measurement of TEWL and so it may not be useful to detect subclinical lesions. 
The set of results obtained showed that for both skin types, subjects who drank kefir for eight weeks presented a significant improvement in skin barrier function. Among volunteers who consumed kefir, it is noteworthy that the greatest improvement in both TEWL and hydration was observed in atopic individuals, especially in the forearm. These results also show the relevance of evaluating different anatomical areas in skin studies. Among all anatomical study areas, the forearm showed to be the most sensitive area in obtaining skin variations, for both TEWL and hydration. Such variations observed in the cutaneous parameters in different anatomical regions may be related to differences in thickness and also at the SC level, namely in ceramides and filaggrin; as well as differences in the cutaneous microcirculation [91]. Probiotics may positively impact the skin by enabling the production of bioactive bacterial compounds such as lactic acid, hyaluronic acid, and SCFA [42,74]. We have previously demonstrated that the kefir produced under home use conditions used in this study fulfills the lactic acid requirement for a fermented product [27].

The concept of hormesis can also contribute to justify our results, since it is a biphasic dose/concentration response, characterized by a low-dose stimulation and a high-dose inhibition, based on adaptive responses of biological systems to moderate or self-imposed environmental challenges, whereby the system improves its functionality and/or tolerance to more severe challenges [92]. Calabrese et al. found that while normal and high-risk groups generally exhibit hormonal dose responses to the same inducing agent, high-risk groups tend to respond better to lower doses [93].

Exposure of probiotic LAB to stressors, both during fermentation and in the gastrointestinal tract, affects its survival, as well as its proliferation and gastrointestinal functionality [94]. In the intestine, the probiotic LAB exhibits substantial antioxidant activity, promoting the production of antioxidant enzymes, thereby helping to remove ROS and alleviating oxidative stress [94]. Furthermore, improved survival of the probiotic LAB during fermentation is achieved by co-culture with initial strains. Given that yeasts have greater antioxidant activity than LAB, when used in co-culture, there is an increase in antioxidant activity, growth rate, and protective effect against oxidative damage [95]. Exposure of a probiotic strain to a sublethal level of oxidative stress will induce an adaptive response and improve the strain's resistance to potentially higher levels of oxidative stress. Probiotic bacteria can exert their antioxidant activity through the scavenging of free radicals, chelation of metal ions, enzymatic regulation, and modulation of the intestinal microbiota [37,94].

It can be highlighted that in $\mathrm{AD}$, chronic skin inflammation is associated with the overproduction of reactive oxygen species (ROS), such as superoxide $\left(\mathrm{O}^{2-}\right)$ and hydrogen peroxide $\left(\mathrm{H}_{2} \mathrm{O}_{2}\right)$, thus generating an oxidative stress condition [96,97]. It is known that mitochondria play an essential role in both homeostasis and inflammatory conditions of the skin [98]; thus, the mitochondrial dysfunction of the skin, caused by the production of ROS, is a potential contributer to the mechanism of AD initiation [99].

The effects observed on skin barrier function in this study can likely be attributed to the combined effects of all kefir ingredients, including its complex microbiota, its metabolites, and macro- and micronutrients resulting from the fermentation, as eating a food promotes a whole-body effect $[38,40,41,100]$.

However, although the kefir grain microbial composition is very stable [55,100], the concentration of metabolites and inhibitory compounds that interact with each other may differ in every fermentation process, thus in part justifying the different results reported in the literature. Of note, no adverse effects were reported during the kefir intake period in this study. In addition, unlike many previous reports, our work was conducted in vivo in humans, which probably highlights the effect of kefir digestion in putative health benefits.

Despite all the positive outcomes found in our study, some limitations must be acknowledged. First, this was not a double-blind, placebo-controlled study. Furthermore, although the study design was intended to minimize the effect of individual variability and the small number of participants, individual changes can occur over time, influencing the dynamics of the gut-skin axis and thus impacting the results [44]. However, these 
challenges can be mitigated by introducing a washout period and collecting new baseline samples before starting a second sequential intervention.

Moreover, although we did not identify any relationship between nutrient intake and the measured skin parameters, that influence is expected to exist due to the impact of food in the gut, particularly fiber and water intake $[2,44]$.

Along with the proven utility of the determination of TEWL and SC hydration, evaluation of the skin barrier function should also include assessment of the content of other relevant components of SC, with a focus on the ceramides profile, as well as a determination of the impact of the probiotic intake in the skin microbiota $[5,14,74,87]$.

The ability of probiotics to modulate the gut microbiota and the immune status suggests that systemic immunomodulation occurs following ingestion $[4,10]$. Although all probiotics must present common properties such as low pathogenicity, resistance to gastric acid and bile salt digestion, and adherence to intestinal mucosa, their clinical effects may be species-dependent $[10,11]$. Therefore, monitoring changes in the human gut microbiome after ingesting a multi-strain probiotic, such as kefir, can provide a better understanding of the mechanisms underlying its many health benefits. Finally, conditions affecting the kefir production, such as the fermentation conditions or origin of the grains, should be considered for in-depth analyses regarding the impact of kefir on health [27].

\section{Conclusions}

We investigated the effects of ingestion of homemade kefir on the skin condition, as well as on the SCORAD Index of the atopic individuals. Our results showed a significant improvement on all skin outcomes and suggest that atopical individuals may benefit from kefir intake, especially regarding their skin hydration. The nutritional and microbial richness of kefir makes its application highly relevant within many sectors of health care.

To the best of our knowledge, this was the first study to provide information regarding the cutaneous impact of the intake of kefir produced in household representative conditions. Furthermore, the simultaneous improvement seen in all skin parameters observed in this study is considered a new finding.

This work opens the possibility of continuing the research of the impact of the probiotic kefir on cutaneous health and its mechanism of action via the gut-skin axis.

Supplementary Materials: The following are available online at https: / www.mdpi.com/article / 10.3390/foods10112794/s1; Table S1: Socio-demographic characteristics of study groups. Table S2: Regular food intake characteristics of study groups. Table S3: Individual variation in skin parameters, between $\mathrm{t} 0$ and $\mathrm{t} 8$.

Author Contributions: Conceptualization, C.R., L.M.R., and P.R.; methodology, E.A. and C.R.; software, E.A. and J.G.; validation, C.R. and P.R.; formal analysis, E.A. and J.G.; investigation, E.A.; data curation, E.A. and J.G.; writing—original draft preparation, E.A. and C.R.; writing-review and editing, P.R., J.G., A.R.B., and L.M.R.; visualization, L.M.R., C.R., and P.R.; supervision, C.R., P.R., and L.M.R..; funding acquisition, C.R., L.M.R., and P.R. All authors have read and agreed to the published version of the manuscript.

Funding: This work was financed by the Foundation for Science and Technology (FCT, Portugal) through projects UIDB/04567/2020 and UIDP/04567/2020 to CBIOS.

Institutional Review Board Statement: The study was conducted according to the guidelines of the Declaration of Helsinki, and approved by the Ethics Committee of the Escola de Ciências e Tecnologias da Saúde da Universidade Lusófona (protocol code 1/2018, date of approval 15/06/2018).

Informed Consent Statement: Informed consent was obtained from all subjects involved in the study.

Data Availability Statement: Data are available from the corresponding author upon reasonable request. 
Acknowledgments: Emília Alves acknowledge ALIES, Portugal for the grant PADDIC 2020-2021. The authors gratefully thank Angela Leon, from the Centro de Investigación y Desarrollo en Criotecnología de Alimentos (CIDCA), Universidad de La Plata, Argentina, for providing the CIDCA AGK1 kefir grains. The authors are grateful to the Foundation for Science and Technology (FCT, Portugal) for financial support through national funds FCT/MCTES to CIMO (UIDB/00690/2020).

Conflicts of Interest: The authors declare no conflict of interest.

\section{References}

1. Stefanovic, N.; Irvine, A.D.; Flohr, C. The Role of the Environment and Exposome in Atopic Dermatitis. Curr. Treat. Options Allergy 2021, 8, 222-241. [CrossRef]

2. Beam, A.; Clinger, E.; Hao, L. Effect of Diet and Dietary Components on the Composition of the Gut Microbiota. Nutrients 2021, 13, 2795. [CrossRef] [PubMed]

3. Boelsma, E.; Hendriks, H.F.J.; Roza, L. Nutritional Skin Care: Health Effects of Micronutrients and Fatty Acids. Am. J. Clin. Nutr. 2001, 73, 853-864. [CrossRef] [PubMed]

4. Salem, I.; Ramser, A.; Isham, N.; Ghannoum, M.A. The Gut Microbiome as a Major Regulator of the Gut-Skin Axis. Front. Microbiol. 2018, 9, 1-14. [CrossRef]

5. Kim, J.; Kim, H. Microbiome of the Skin and Gut in Atopic Dermatitis (AD): Understanding the Pathophysiology and Finding Novel Management Strategies. J. Clin. Med. 2019, 8, 444. [CrossRef] [PubMed]

6. Lee, S.-Y.; Lee, E.; Park, Y.M.; Hong, S.J. Gut-Skin Axis in Atopic Dermatitis. Allergy Asthma Immunol Res 2018, 10, 354-362. [CrossRef] [PubMed]

7. Simonyte Sjödin, K.; Vidman, L.; Rydén, P.; West, C.E. Emerging Evidence of the Role of Gut Microbiota in the Development of Allergic Diseases. Curr. Opin. Allergy Clin. Immunol. 2016, 16, 390-395. [CrossRef]

8. Bosman, E.S.; Albert, A.Y.; Lui, H.; Dutz, J.P.; Vallance, B.A. Skin Exposure to Narrow Band Ultraviolet (Uvb) Light Modulates the Human Intestinal Microbiome. Front. Microbiol. 2019, 10, 1-11. [CrossRef]

9. O'Neill, C.A.; Monteleone, G.; McLaughlin, J.T.; Paus, R. The Gut-Skin Axis in Health and Disease: A Paradigm with Therapeutic Implications. BioEssays 2016, 38, 1167-1176. [CrossRef]

10. Wieërs, G.; Belkhir, L.; Enaud, R.; Leclercq, S.; Philippart de Foy, J.-M.; Dequenne, I.; de Timary, P.; Cani, P.D. How Probiotics Affect the Microbiota. Front. Cell. Infect. Microbiol. 2020, 9, 454. [CrossRef]

11. Makrgeorgou, A.; Leonardi-Bee, J.; Bath-Hextall, F.J.; Murrell, D.F.; Tang, M.L.K.; Roberts, A.; Boyle, R.J. Probiotics for Treating Eczema. Cochrane Database Syst. Rev. 2018, 2018, CD006135. [CrossRef]

12. Hill, C.; Guarner, F.; Reid, G.; Gibson, G.R.; Merenstein, D.J.; Pot, B.; Morelli, L.; Canani, R.B.; Flint, H.J.; Salminen, S.; et al. Expert Consensus Document: The International Scientific Association for Probiotics and Prebiotics Consensus Statement on the Scope and Appropriate Use of the Term Probiotic. Nat. Rev. Gastroenterol. Hepatol. 2014, 11, 506-514. [CrossRef]

13. Chang, Y.S.; Trivedi, M.K.; Jha, A.; Lin, Y.F.; Dimaano, L.; García-Romero, M.T. Synbiotics for Prevention and Treatment of Atopic Dermatitis: A Meta-Analysis of Randomized Clinical Trials. JAMA Pediatr. 2016, 170, 236-242. [CrossRef]

14. Kim, J.; Kim, B.E.; Leung, D.Y.M. Pathophysiology of Atopic Dermatitis: Clinical Implications. Allergy Asthma Proc. 2019, 40, 84-92. [CrossRef]

15. Kim, B.E.; Leung, D.Y.M.M. Significance of Skin Barrier Dysfunction in Atopic Dermatitis. Allergy. Asthma Immunol. Res. 2018, 10, 207-215. [CrossRef] [PubMed]

16. Petersen, E.B.M.; Skov, L.; Thyssen, J.P.; Jensen, P. Role of the Gut Microbiota in Atopic Dermatitis: A Systematic Review. Acta Derm. Venereol. 2018, 99, 5-11. [CrossRef] [PubMed]

17. Lolou, V.; Panayiotidis, M.I. Functional Role of Probiotics and Prebiotics on Skin Health and Disease. Fermentation $2019,5,41$. [CrossRef]

18. Finch, J.; Munhutu, M.N.; Whitaker-Worth, D.L. Atopic Dermatitis and Nutrition. Clin. Dermatol. 2010, 28, 605-614. [CrossRef] [PubMed]

19. Zhao, M.; Shen, C.; Ma, L. Treatment Efficacy of Probiotics on Atopic Dermatitis, Zooming in on Infants: A Systematic Review and Meta-Analysis. Int. J. Dermatol. 2018, 57, 635-641. [CrossRef] [PubMed]

20. Leite, A.M.d.O.; Miguel, M.A.L.; Peixoto, R.S.; Rosado, A.S.; Silva, J.T.; Paschoalin, V.M.F. Microbiological, Technological and Therapeutic Properties of Kefir: A Natural Probiotic Beverage. Brazilian J. Microbiol. 2013, 2, 341-349. [CrossRef]

21. Farnworth, E.R. Kefir-A Complex Probiotic. Food Sci. Technol. Bull. Funct. Foods 2005, 2, 1-17. [CrossRef]

22. Aryana, K.J.; Olson, D.W. A 100-Year Review: Yogurt and Other Cultured Dairy Products. J. Dairy Sci. 2017, 100, 9987-10013. [CrossRef]

23. Yang, Y.; Shevchenko, A.; Knaust, A.; Abuduresule, I.; Li, W.; Hu, X.; Wang, C.; Shevchenko, A. Proteomics Evidence for Kefir Dairy in Early Bronze Age China. J. Archaeol. Sci. 2014, 45, 178-186. [CrossRef]

24. Garrote, G.L.; Abraham, A.G.; De Antoni, G.L. Inhibitory Power of Kefir: The Role of Organic Acids. J. Food Prot. 2000, 63, 364-369. [CrossRef] [PubMed]

25. Prado, M.R.; Blandón, L.M.; Vandenberghe, L.P.S.; Rodrigues, C.; Castro, G.R.; Thomaz-Soccol, V.; Soccol, C.R. Milk Kefir: Composition, Microbial Cultures, Biological Activities, and Related Products. Front. Microbiol. 2015, 6, 1177. [CrossRef] [PubMed] 
26. Maeda, H.; Zhu, X.; Omura, K.; Suzuki, S.; Kitamura, S. Effects of an Exopolysaccharide (Kefiran) on Lipids, Blood Pressure, Blood Glucose, and Constipation. BioFactors 2004, 22, 197-200. [CrossRef]

27. Alves, E.; Ntungwe, E.N.; Gregório, J.; Rodrigues, L.M.; Pereira-Leite, C.; Caleja, C.; Pereira, E.; Barros, L.; Aguilar-Vilas, M.V.; Rosado, C.; et al. Characterization of Kefir Produced in Household Conditions: Physicochemical and Nutritional Profile, and Storage Stability. Foods 2021, 10, 1057. [CrossRef]

28. Slattery, C.; Cotter, P.D.; O'Toole, P.W. Analysis of Health Benefits Conferred by Lactobacillus Species from Kefir. Nutrients 2019, 11, 1252. [CrossRef] [PubMed]

29. Rosa, D.D.; Dias, M.M.S.; Grześkowiak, Ł.M.; Reis, S.A.; Conceição, L.L.; Peluzio, M.D.C.G. Milk Kefir: Nutritional, Microbiological and Health Benefits. Nutr. Res. Rev. 2017, 30, 82-96. [CrossRef]

30. Bourrie, B.C.T.; Willing, B.P.; Cotter, P.D. The Microbiota and Health Promoting Characteristics of the Fermented Beverage Kefir. Front. Microbiol. 2016, 7, 647. [CrossRef]

31. Kesenkaş, H.; Gürsoy, O.; Özbaş, H. Kefir. In Fermented Foods in Health and Disease Prevention; Elsevier Inc.: Amsterdam, The Netherlands, 2016; pp. 339-361.

32. Guzel-Seydim, Z.B.; Kok-Tas, T.; Greene, A.K.; Seydim, A.C. Review: Functional Properties of Kefir. Crit. Rev. Food Sci. Nutr. 2011, 51, 261-268. [CrossRef]

33. Azizi, N.F.; Kumar, M.R.; Yeap, S.K.; Abdullah, J.O.; Khalid, M.; Omar, A.R.; Osman, M.A.; Mortadza, S.A.S.; Alitheen, N.B. Kefir and Its Biological Activities. Foods 2021, 10, 1210. [CrossRef]

34. Rodrigues, K.L.; Carvalho, J.C.T.; Schneedorf, J.M. Anti-Inflammatory Properties of Kefir and Its Polysaccharide Extract. Inflammopharmacology 2005, 13, 485-492. [CrossRef]

35. Rodrigues, K.L.; Caputo, L.R.; Carvalho, J.C.; Evangelista, J.; Schneedorf, J.M. Antimicrobial and Healing Activity of Kefir and Kefiran Extract. Int. J. Antimicrob. Agents 2005, 25, 404-408. [CrossRef]

36. Carasi, P.; Racedo, S.M.; Jacquot, C.; Romanin, D.E.; Serradell, M.A.; Urdaci, M.C. Impact of Kefir Derived Lactobacillus Kefiri on the Mucosal Immune Response and Gut Microbiota. J. Immunol. Res. 2015, 2015, 1-12. [CrossRef]

37. Wang, Y.; Wu, Y.; Wang, Y.; Xu, H.; Mei, X.; Yu, D.; Wang, Y.; Li, W. Antioxidant Properties of Probiotic Bacteria. Nutrients 2017, 9 , 521. [CrossRef]

38. Iraporda, C.; Abatemarco Júnior, M.; Neumann, E.; Nunes, Á.C.; Nicoli, J.R.; Abraham, A.G.; Garrote, G.L. Biological Activity of the Non-Microbial Fraction of Kefir: Antagonism against Intestinal Pathogens. J. Dairy Res. 2017, 84, 339-345. [CrossRef] [PubMed]

39. Huseini, H.F.; Rahimzadeh, G.; Fazeli, M.R.; Mehrazma, M.; Salehi, M. Evaluation of Wound Healing Activities of Kefir Products. Burns 2012, 38, 719-723. [CrossRef] [PubMed]

40. Garrote, G.L.; Abraham, A.G.; De Antoni, G.L. Microbial Interactions in Kefir: A Natural Probiotic Drink. Biotechnol. Lact. Acid Bact. Nov. Appl. 2010, 327-340. [CrossRef]

41. Bengoa, A.A.; Iraporda, C.; Garrote, G.L.; Abraham, A.G. Kefir Micro-Organisms: Their Role in Grain Assembly and Health Properties of Fermented Milk. J. Appl. Microbiol. 2019, 126, 686-700. [CrossRef] [PubMed]

42. Jones, R.M. The Influence of the Gut Microbiota on Host Physiology: In Pursuit of Mechanisms. Yale J. Biol. Med. 2016, 89, 285-297. [PubMed]

43. Stiemsma, L.T.; Nakamura, R.E.; Nguyen, J.G.; Michels, K.B. Does Consumption of Fermented Foods Modify the Human Gut Microbiota? J. Nutr. 2020, 150, 1680-1692. [CrossRef] [PubMed]

44. Healey, G.R.; Murphy, R.; Brough, L.; Butts, C.A.; Coad, J. Interindividual Variability in Gut Microbiota and Host Response to Dietary Interventions. Nutr. Rev. 2017, 75, 1059-1080. [CrossRef] [PubMed]

45. Fitzpatrick, T. The Validity and Practicality of Sun-Reactive Skin Types I through VI. Arch. Dermatol. 1988, 124, 869-871. [CrossRef]

46. World Health Organization (WHO). Body Mass Index-BMI. Available online: https://www.euro.who.int/en/health-topics/ disease-prevention/nutrition/a-healthy-lifestyle/body-mass-index-bmi (accessed on 16 October 2019).

47. Saito, Y.; Mihara, T.; Maruyama, K.; Saito, J.; Ikeda, M.; Tomonaga, A.; Kumagai, T. Effects of Intake of Lactobacillus Casei Subsp. Casei 327 on Skin Conditions: A Randomized, Double-Blind, Placebo-Controlled, Parallel-Group Study in Women. Biosci. Microbiota Food Health 2017, 36, 111-120. [CrossRef]

48. Gueniche, A.; Philippe, D.; Bastien, P.; Reuteler, G.; Blum, S.; Castiel-Higounenc, I.; Breton, L.; Benyacoub, J. Randomised Double-Blind Placebo-Controlled Study of the Effect of Lactobacillus Paracasei NCC 2461 on Skin Reactivity. Benef. Microbes 2014, 5, 137-145. [CrossRef]

49. Ogawa, M.; Saiki, A.; Matsui, Y.; Tsuchimoto, N.; Nakakita, Y.; Takata, Y.; Nakamura, T. Effects of Oral Intake of Heat-Killed Lactobacillus Brevis SBC8803 (SBL88 ${ }^{\mathrm{TM}}$ ) on Dry Skin Conditions: A Randomized, Double-Blind, Placebo-Controlled Study. Exp. Ther. Med. 2016, 12, 3863-3872. [CrossRef]

50. Roessler, A.; Friedrich, U.; Vogelsang, H.; Bauer, A.; Kaatz, M.; Hipler, U.C.; Schmidt, I.; Jahreis, G. The Immune System in Healthy Adults and Patients with Atopic Dermatitis Seems to Be Affected Differently by a Probiotic Intervention. Clin. Exp. Allergy 2008, 38, 93-102. [CrossRef]

51. Yoshida, Y.; Seki, T.; Matsunaka, H.; Watanabe, T.; Shindo, M.; Yamada, N.; Yamamoto, O. Clinical Effects of Probiotic Bifidobacterium Breve Supplementation in Adult Patients with Atopic Dermatitis. Yonago Acta Med. 2010, 53, 37-45. 
52. Matsumoto, M.; Ebata, T.; Hirooka, J.; Hosoya, R.; Inoue, N.; Itami, S.; Tsuji, K.; Yaginuma, T.; Muramatsu, K.; Nakamura, A.; et al. Antipruritic Effects of the Probiotic Strain LKM512 in Adults with Atopic Dermatitis. Ann. Allergy Asthma Immunol. 2014, 113, 209-216. [CrossRef]

53. Illner, A.-K.; Nöthlings, U.; Wagner, K.; Ward, H.; Boeing, H. The Assessment of Individual Usual Food Intake in Large-Scale Prospective Studies. Ann. Nutr. Metab. 2010, 56, 99-105. [CrossRef] [PubMed]

54. Rutishauser, I.H. Dietary Intake Measurements. Public Health Nutr. 2005, 8, 1100-1107. [CrossRef] [PubMed]

55. Garrote, G.L.L.; Abraham, A.G.G.; De Antoni, G.L.L. Preservation of Kefir Grains, a Comparative Study. LWT—Food Sci. Technol. 1997, 30, 77-84. [CrossRef]

56. Garrote, G.L.; Abraham, A.G.; De Antoni, G.L. Chemical and Microbiological Characterisation of Kefir Grains. J. Dairy Res. 2001, 68, 639-652. [CrossRef]

57. Diosma, G.; Romanin, D.E.; Rey-Burusco, M.F.; Londero, A.; Garrote, G.L. Yeasts from Kefir Grains: Isolation, Identification, and Probiotic Characterization. World J. Microbiol. Biotechnol. 2014, 30, 1-11. [CrossRef]

58. Ouwehand, A.C. A Review of Dose-Responses of Probiotics in Human Studies. Benef. Microbes 2017, 8, 143-151. [CrossRef]

59. Terpou, A.; Papadaki, A.; Lappa, I.K.; Kachrimanidou, V.; Bosnea, L.A.; Kopsahelis, N. Probiotics in Food Systems: Significance and Emerging Strategies towards Improved Viability and Delivery of Enhanced Beneficial Value. Nutrients 2019, $11,1591$. [CrossRef] [PubMed]

60. Polańska, A.; Dańczak-Pazdrowska, A.; Silny, W.; Jenerowicz, D.; Osmola-Mańkowska, A.; Olek-Hrab, K. Evaluation of Selected Skin Barrier Functions in Atopic Dermatitis in Relation to the Disease Severity and Pruritus. Adv. Dermatology Allergol. Postepy Dermatologii Alergol. 2012, 29, 373-377. [CrossRef]

61. Kim, D.W.; Park, J.Y.; Na, G.Y.; Lee, S.J.; Lee, W.J. Correlation of Clinical Features and Skin Barrier Function in Adolescent and Adult Patients with Atopic Dermatitis. Int. J. Dermatol. 2006, 45, 698-701. [CrossRef]

62. Sotoodian, B.; Maibach, H.I. Noninvasive Test Methods for Epidermal Barrier Function. Clin. Dermatol. 2012, 30, 301-310. [CrossRef]

63. Alves, E.; Rijo, P.; Rodrigues, L.M.; Rosado, C. Determination of Relevant Endpoints to Evaluate the in Vivo Barrier Function in Cutaneous Health. Biomed. Biopharm. Res. 2019, 16, 80-88. [CrossRef]

64. Rogiers, V. EEMCO Guidance for the Assessment of the Transepidermal Water Loss (TEWL) in Cosmetic Sciences. Skin Pharmacol. Appl. Skin Physiol. 2001, 14, 117-128. [CrossRef]

65. Qassem, M.; Kyriacou, P. Review of Modern Techniques for the Assessment of Skin Hydration. Cosmetics 2019, 6, 19. [CrossRef]

66. Fullerton, A.; Fischer, T.; Lahti, A.; Wlihelm, K.; Takiwaki, H.; Serup, J. Guidelines for Measurements Skin Colour and ErythemaA Report from the Standardization Group of the European Society of Contact Dermatitis. Contact Dermat. 1996, 35, 1-10. [CrossRef]

67. European Task Force on Atopic Dermatitis Clinical and Laboratory Investigations European Task Force on Atopic Dermatitis Atopic Dermatitis Eczema Scoring Composite Index Severity. Dermatology 1993, 186, 23-31. [CrossRef]

68. Oranje, A.P. Practical Issues on Interpretation of Scoring Atopic Dermatitis: SCORAD Index, Objective SCORAD, Patient-Oriented SCORAD and Three-Item Severity Score. Curr. Probl. Dermatol. 2011, 41, 149-155. [CrossRef] [PubMed]

69. World Health Organization (WHO). Waist Circumference and Waist-Hip Ratio: Report of a WHO Expert Consultation; World Health Organization (WHO): Geneva, Switzerland, 2011; ISBN 9789241501491.

70. European Food Safety Authority (EFSA). Dietary Reference Values for Nutrients Summary Report. EFSA Support. Publ. 2017, 14, e15121E. [CrossRef]

71. Sonnenburg, J.L.; Bäckhed, F. Diet-Microbiota Interactions as Moderators of Human Metabolism. Nature 2016, 535, 56-64. [CrossRef] [PubMed]

72. Shi, Z.; Wu, X.; Yu, S.; Huynh, M.; Jena, P.K.; Nguyen, M.; Wan, Y.J.Y.; Hwang, S.T. Short-Term Exposure to a Western Diet Induces Psoriasiform Dermatitis by Promoting Accumulation of IL-17A-Producing $\Gamma \delta$ T Cells. J. Invest. Dermatol. 2020, 140, 1815-1823. [CrossRef]

73. Rusu, E.; Enache, G.; Cursaru, R.; Alexescu, A.; Radu, R.; Onila, O.; Cavallioti, T.; Rusu, F.; Posea, M.; Jinga, M.; et al. Prebiotics and Probiotics in Atopic Dermatitis (Review). Exp. Ther. Med. 2019, 18, 926-931. [CrossRef] [PubMed]

74. Lew, L.C.; Liong, M.T. Bioactives from Probiotics for Dermal Health: Functions and Benefits. J. Appl. Microbiol. 2013, 114, 1241-1253. [CrossRef]

75. Notay, M.; Foolad, N.; Vaughn, A.R.; Sivamani, R.K. Probiotics, Prebiotics, and Synbiotics for the Treatment and Prevention of Adult Dermatological Diseases. Am. J. Clin. Dermatol. 2017, 18, 721-732. [CrossRef]

76. Peluzio, M.d.C.G.; Dias, M.d.M.; Martinez, J.A.; Milagro, F.I. Kefir and Intestinal Microbiota Modulation: Implications in Human Health. Front. Nutr. 2021, 8, 1-15. [CrossRef] [PubMed]

77. Dimidi, E.; Cox, S.; Rossi, M.; Whelan, K. Fermented Foods: Definitions and Characteristics, Gastrointestinal Health and Disease Nutrients 2019, 11, 1806. [CrossRef]

78. Kim, D.H.; Jeong, D.; Kim, H.; Seo, K.H. Modern Perspectives on the Health Benefits of Kefir in next Generation Sequencing Era: Improvement of the Host Gut Microbiota. Crit. Rev. Food Sci. Nutr. 2019, 59, 1782-1793. [CrossRef] [PubMed]

79. Üstün-Aytekin, Ö.; Şeker, A.; Arısoy, S. The Effect of in Vitro Gastrointestinal Simulation on Bioactivities of Kefir. Int. J. Food Sci. Technol. 2020, 55, 283-292. [CrossRef] 
80. Lee, D.E.; Huh, C.-S.; Ra, J.; Choi, I.-D.; Jeong, J.-W.; Kim, S.-H.; Ryu, J.H.; Seo, Y.K.; Koh, J.S.; Lee, J.-H.; et al. Clinical Evidence of Effects of Lactobacillus Plantarum HY7714 on Skin Aging: A Randomized, Double Blind, Placebo-Controlled Study. J. Microbiol. Biotechnol. 2015, 25, 2160-2168. [CrossRef]

81. Mori, N.; Kano, M.; Masuoka, N.; Konno, T.; Suzuki, Y.; Miyazaki, K.; Ueki, Y. Effect of Probiotic and Prebiotic Fermented Milk on Skin and Intestinal Conditions in Healthy Young Female Students. Biosci. Microbiota Food Health 2016, 35, 105-112. [CrossRef]

82. Kano, M.; Masuoka, N.; Kaga, C.; Sugimoto, S.; Iizuka, R.; Manabe, K.; Sone, T.; Oeda, K.; Nonoka, C.; Miyazaki, K.; et al. Consecutive Intake of Fermented Milk Containing Bifidobacterium Breve Strain Yakult and Galacto-Oligosaccharides Benefits Skin Condition in Healthy Adult Women. Biosci. Microbiota Food Health 2013, 21, 33-39. [CrossRef] [PubMed]

83. Kim, H.-J.; Kim, Y.-J.; Kang, M.-J.; Seo, J.-H.; Kim, H.-Y.; Jeong, S.K.; Lee, S.-H.; Kim, J.-M.; Hong, S.-J. A Novel Mouse Model of Atopic Dermatitis with Epicutaneous Allergen Sensitization and the Effect of Lactobacillus Rhamnosus. Exp. Dermatol. 2012, 21, 672-675. [CrossRef]

84. Baba, H.; Masuyama, A.; Yoshimura, C.; Aoyama, Y.; Takano, T.; Ohki, K. Oral Intake of Lactobacillus Helveticus-Fermented Milk Whey Decreased Transepidermal Water Loss and Prevented the Onset of Sodium Dodecylsulfate-Induced Dermatitis in Mice. Biosci. Biotechnol. Biochem. 2010, 74, 18-23. [CrossRef] [PubMed]

85. Ellis, S.R.; Nguyen, M.; Vaughn, A.R.; Notay, M.; Burney, W.A.; Sandhu, S.; Sivamani, R.K. The Skin and Gut Microbiome and Its Role in Common Dermatologic Conditions. Microorganisms 2019, 7, 550. [CrossRef]

86. Rather, I.A.; Bajpai, V.K.; Kumar, S.; Lim, J.; Paek, W.K.; Park, Y.H. Probiotics and Atopic Dermatitis: An Overview. Front. Microbiol. 2016, 7, 1-7. [CrossRef] [PubMed]

87. Kim, S.O.; Ah, Y.M.; Yu, Y.M.; Choi, K.H.; Shin, W.G.; Lee, J.Y. Effects of Probiotics for the Treatment of Atopic Dermatitis: A Meta-Analysis of Randomized Controlled Trials. Ann. Allergy Asthma Immunol. 2014, 113, 217-226. [CrossRef] [PubMed]

88. Drago, L.; Iemoli, E.; Rodighiero, V.; Nicola, L.; De Vecchi, E.; Piconi, S. Effects of Lactobacillus Salivarius LS01 (DSM 22775) Treatment on Adult Atopic Dermatitis: A Randomized Placebo-Controlled Study. Int. J. Immunopathol. Pharmacol. 2011, 24, 1037-1048. [CrossRef]

89. Holm, E.A.; Wulf, H.C.; Thomassen, L.; Jemec, G.B.E. Assessment of Atopic Eczema: Clinical Scoring and Noninvasive Measurements. Br. J. Dermatol. 2007, 157, 674-680. [CrossRef] [PubMed]

90. Iemoli, E.; Trabattoni, D.; Parisotto, S.; Borgonovo, L.; Toscano, M.; Rizzardini, Z.; Clerici, M.; Ricci, E.; Fusi, A.; De Vecchi, E.; et al. Probiotics Reduce Gut Microbial Translocation and Improve Adult Atopic Dermatitis. J. Clin. Gastroenterol. 2012, 46, S33-S40. [CrossRef] [PubMed]

91. Proksch, E.; Fölster-Holst, R.; Bräutigam, M.; Sepehrmanesh, M.; Pfeiffer, S.; Jensen, J.M. Role of the Epidermal Barrier in Atopic Dermatitis: Academy CME. JDDG-J. Ger. Soc. Dermatol. 2009, 7, 899-911. [CrossRef]

92. Calabrese, E.J.; Mattson, M.P.; Dhawan, G.; Kapoor, R.; Calabrese, V.; Giordano, J. Hormesis: A Potential Strategic Approach to the Treatment of Neurodegenerative Disease. Int. Rev. Neurobiol. 2020, 155, 271-301. [CrossRef]

93. Calabrese, E.J.; Baldwin, L.A. Defining Hormesis. Hum. Exp. Toxicol. 2002, 21, 91-97. [CrossRef]

94. Feng, T.; Wang, J. Oxidative Stress Tolerance and Antioxidant Capacity of Lactic Acid Bacteria as Probiotic: A Systematic Review. Gut Microbes 2020, 12, 1-24. [CrossRef] [PubMed]

95. Odamaki, T.; Xiao, J.Z.; Yonezawa, S.; Yaeshima, T.; Iwatsuki, K. Improved Viability of Bifidobacteria in Fermented Milk by Cocultivation with Lactococcus Lactis Subspecies Lactis. J. Dairy Sci. 2011, 94, 1112-1121. [CrossRef]

96. Ji, H.; Li, X.-K. Oxidative Stress in Atopic Dermatitis. Oxid. Med. Cell. Longev. 2016, 2016, 2721469. [CrossRef]

97. Bertino, L.; Guarneri, F.; Cannavò, S.P.; Casciaro, M.; Pioggia, G.; Gangemi, S. Oxidative Stress and Atopic Dermatitis. Antioxidants 2020, 9, 196. [CrossRef] [PubMed]

98. Lisowski, P.; Kannan, P.; Mlody, B.; Prigione, A. Mitochondria and the Dynamic Control of Stem Cell Homeostasis. EMBO Rep. 2018, 19, e45432. [CrossRef] [PubMed]

99. Sreedhar, A.; Aguilera-Aguirre, L.; Singh, K.K. Mitochondria in Skin Health, Aging, and Disease. Cell Death Dis. 2020, 11, 444. [CrossRef] [PubMed]

100. Vardjan, T.; Mohar Lorbeg, P.; Rogelj, I.; Čanžek Majhenič, A. Characterization and Stability of Lactobacilli and Yeast Microbiota in Kefir Grains. J. Dairy Sci. 2013, 96, 1-8. [CrossRef] 